\title{
Photoelastic analysis of stress generated by a silorane-based restoration system
}

\section{Murilo Baena Lopes ${ }^{(a)}$ \\ Natália Valarini (a) \\ Sandra Kiss Moura(a) \\ Ricardo Danil Guiraldo(a) \\ Alcides Gonini Júnior ${ }^{(a)}$}

(a) Department of Restorative Dentistry, School of Dentistry, University North of Parana, Londrina, PR, Brazil.
Declaration of Interests: The authors certify that they have no commercial or associative interest that represents a conflict of interest in connection with the manuscript.

\section{Corresponding author:}

Murilo Baena Lopes

E-mail: baenalopes@yahoo.com.br

Received for publication on Feb 24, 2011 Accepted for publication on Jun 16, 2011

\begin{abstract}
Silorane-based composite, an epoxy material, was marketed as promising less polymerization contraction than conventional restorative materials. The aim of this study was to evaluate, by means of photoelasticity, the polymerization stress generated by a silorane-based composite. Thirty photoelastic rings with orifices measuring $5 \mathrm{~mm}(\mathrm{~d}) \times 3 \mathrm{~mm}(\mathrm{~h})$ were prepared and divided into 6 groups $(\mathrm{n}=5)$ according to the material tested. The inside walls of the rings were sandblasted with aluminum oxide, after which the restorative materials were inserted into the orifices and photoactivated according to the manufacturer's instructions. The specimens were analyzed and the visual representation of the stress was measured considering the isochromatic ring of first order. The data were converted to MPa and subjected to ANOVA and Tukey's test $(\alpha=0.05)$. The adhesive Filtek P-90 (G5) showed high contraction stress $(\mathrm{p}<0.05)$ when compared to G1, G2, G3, G4, and G6, which did not differ from each other $(\mathrm{p}>0.05)$. The composite Filtek P-90 showed similar contraction stress compared to the conventional composite and, additionally, its adhesive showed higher stress than did the etch-and-rinse 2-step adhesive.
\end{abstract}

Descriptors: Composite Resins; Adhesives; Dental Stress Analysis; Polymerization.

\section{Introduction}

Composite resins are used worldwide as well-established restorative materials. ${ }^{1}$ The polymerization reaction of these materials occurs through a repetitive molecular process in which monomers are converted to a covalently bonded network, thus forming polymer chains. Contraction of these materials occurs when the distances between monomers associated with Van der Waals forces are reduced due to formation of covalent bonds during the polymerization process. In addition, there is less distance between molecules when materials are in the solid state as compared to the liquid state. Then, contraction occurs during composite polymerization as a chemical function of synthetic resins. ${ }^{2}$

Contraction due to polymerization is not problematic when it occurs on an unbonded surface; however, stress is generated at a cavity interface as a result of the forces generated by the contraction of the composite bonded to the dental structure. ${ }^{3,4}$ The bond between cementum or dentin and resinous restorative systems still presents challenges due to polym- 
erization contraction, despite the efforts to improve the bond of adhesive systems. ${ }^{5} \mathrm{~A}$ new material based on silorane that promises low rates of polymerization contraction has been developed and launched on the market.

Some studies ${ }^{6-8}$ have suggested that factors such as cavity configuration, setting mechanisms, filler type, polymerization degree, ${ }^{9}$ and insertion technique influence the development of contraction stress. One possible way of reducing this stress is to reduce the polymerization rate. ${ }^{10,11}$ Feltzer et al..$^{7}$ showed that chemically-activated composites adapt better and exhibit less microleakage than do photoactivated composites. These results have been explained by the differences in the contraction stress induced by the polymerization contraction. ${ }^{12}$ Versluis et al. ${ }^{13}$ studied the vectors of contraction between chemically- and photoactivated composites using finite element analysis and found few differences between them.

Researchers have also measured the stress developed in a cavity using a tensiometer..$^{3,4,7,14}$ Feltzer et $a l{ }^{7}$ suggested that the magnitude of the stress depends on the cavity's three-dimensional configuration, and that the concept of cavity configuration (C-factor) is important in understanding the development of the composite stress contraction. The Cfactor concept has been extended to cavity preparation, indicating that different preparation designs are proportional to the stress they generate. ${ }^{15}$ However, contraction stress is not equally distributed about the cavity because of non-uniform contraction of the composites. ${ }^{13}$ When using a two-dimensional cavity, the highest internal stresses were found near the internal angles of the opposite walls. ${ }^{12}$

Photoelastic analysis was used to analyze contraction stress in this study. The internal stresses of the photoelastic material are transformed by visible light, which indicates the location and the magnitude of the stress. In the literature, the stress generated on inlays, onlays, crowns, posts, abutments, and implants has been analyzed through photoelastic analysis. ${ }^{16,17}$ Polymethyl methacrylate (PMMA), with a photoelastic constant of $f_{\sigma}=230 \mathrm{~N} / \mathrm{mm}^{1}$, has been used for photoelastic investigation of photoactivated materials. Photoelastic materials with a low photoelastic constant $\left(f_{\sigma}=10.5 \mathrm{~N} / \mathrm{mm}\right)$ and elastic modulus $(3.400 \mathrm{MPa})^{1}$ allow the determination of isochromatic rings, from which the stress may be determined. ${ }^{5}$

The null hypothesis to be tested is that there are no differences in contraction stress between the different materials.

\section{Methodology}

Circular rings of photoelastic resin (GIII flexible, Polipox, São Paulo, Brazil) were fabricated with the following dimensions: $5 \mathrm{~mm}(\mathrm{~d}) \times 3 \mathrm{~mm}$ (h). After polymerization of the photoelastic resin, the internal walls were sandblasted with $50 \mu \mathrm{m}$ alumina particles in order to obtain higher micromechanical retention. The rings (Figure 1) were divided into 6 groups ( $\mathrm{n}=5$ for each group):

- G1 - conventional composite Filtek Z-350 (3M

Espe, Saint Paul, USA),

- G2 - silorano-based composite Filtek P-90 (3M Espe, Saint Paul, USA),

- G3 - conventional composite Z-350 flow (3M Espe, Saint Paul, USA),

- G4 - primer Filtek P-90 (3M Espe, Saint Paul, USA),

- G5 - adhesive Filtek P-90 (3M Espe, Saint Paul, USA), G6 - adhesive Single Bond 2 (3M Espe,

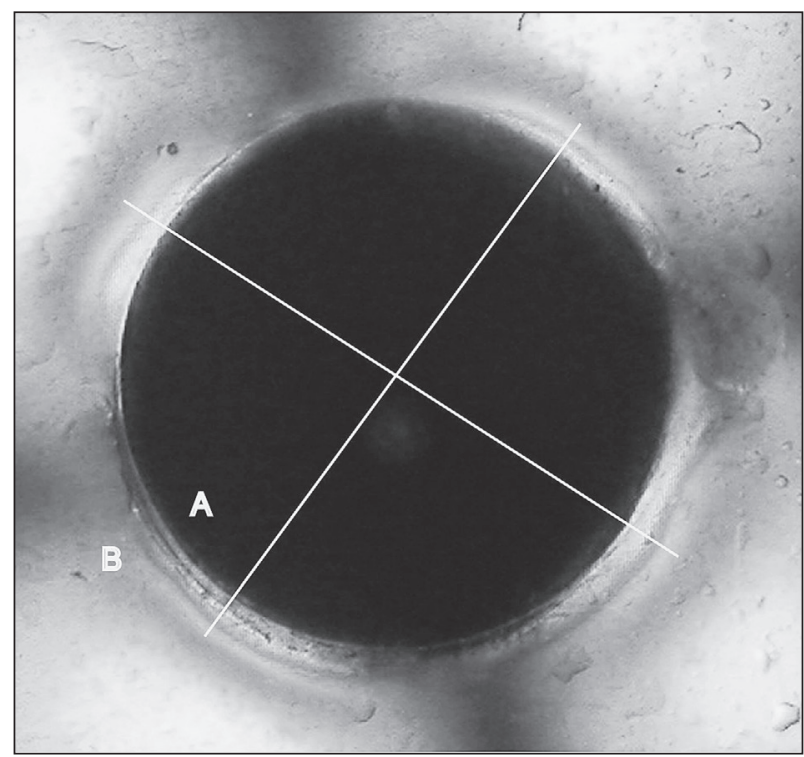

Figure 1 - Representative specimen. A - Tested material (composite, adhesive or primer). B - Photoelastic resin. Isochromatic ring diameter is represented by white lines. 
Saint Paul, USA).

Photoelastic images were recorded in a photoelastic station composed of a filter (Linos Photonics GmbH, Göttingen, Germany) positioned in an exact angulation to visualize the polychromatic fields. The images were converted to isochromatic images through a specific red filter. A light source under the filter promoted illumination of the specimens.

Stress investigations through photoelasticity are based on the following principal equation:

$$
\sigma_{0}=\delta_{\mathrm{x}} \mathrm{D}_{\mathrm{x}}^{2} / \mathrm{D}_{\mathrm{i}}^{2} f_{\mathrm{\sigma}} / 2 \mathrm{~d}
$$

where:

$\mathrm{D}^{2}{ }_{\mathrm{x}}=$ isochromatic ring diameter in $\mathrm{mm}$

(Figure 1),

$\mathrm{D}^{2}{ }_{\mathrm{i}}=$ composite specimen diameter in $\mathrm{mm}$,

$f_{\sigma}=$ photoelastic constant and

$\mathrm{d}=$ photoelastic resin thickness in $\mathrm{mm} .{ }^{18}$

Contraction stress $(\mathrm{MPa})$ was calculated based on the location and diameter of the isochromatic fringe of the first order, obtained from the photoelastic resin through measurements made using UTHSCSA Imagetool software (Department of Dental Diagnostic Science, The University of Texas Health Science Center, San Antonio, USA). The means of the perpendicular diagonals were considered for the calculations. The data were subjected to the Kolmogorov-Smirnov test for normality, and then to Analysis of Variance and Tukey's test at 5\% significance levels.

\section{Results}

The adhesive Filtek P-90 (G5 - $3.12 \pm 0.63$ ) showed higher contraction stress $(\mathrm{p}<0.05)$ than the composite Z-350 (G1 - $1.75 \pm 0.01$ ), the composite Filtek P-90 (G2 - $1.76 \pm 0.02$ ), the composite Z-350 flow (G3 - $1.77 \pm 0.02$ ), the primer Filtek P-90 (G4 $-2.00 \pm 0.05)$ and adhesive Single bond 2 (G6 - $1.91 \pm 0.06)$, which did not differ between each other $(\mathrm{p}>0.05)$.

\section{Discussion}

Each of the components of the restoration sys- tems (Filtek P-90, Filtek Z-350, and Filtek Z-350 flow) was tested individually in order to determine which was primarily responsible for the contraction stress generated. It is well known that the adhesive layer is much thinner than the composite layers of a restoration, thus its influence on the final contraction stress is expected to be lower.

The evaluation of contraction stress of polymeric materials in dentistry is usually performed using a tensiometer. The contraction stress measured by this equipment can be used to express the maximum stress of the specimen under specific conditions; however, the stress near the external margins of the cavity is different from that on the pulpal wall. The distribution of internal stress on the composite restoration must be considered when contraction stress is analyzed. ${ }^{19}$

Some authors have analyzed contraction stress by means of finite element analysis and the theory of elasticity; ${ }^{20}$ however, the results were specific to the approximated data and conception of the analysed material, considering the high variation of the results obtained. ${ }^{19}$ The stress generated in a complex restoration configuration can be determined through the theory of elasticity; however, the results of such calculations are extremely difficult to interpret.

The photoelastic method is simpler than many others used, and is appropriate for the purpose of evaluating contraction stress. The specimens in the photoelastic test used were round and uniform (Figure 1), permitting the variable of irregular stress distribution to be eliminated, and making it possible to obtain data regarding diameter and fringes that were used for the final stress calculations.

Although some studies described a lower contraction stress ${ }^{21}$ and lower cusp deflection ${ }^{22}$ for restorative systems based on silorane, the Filtek P-90 did not show reduced contraction stress when compared to the nanoparticle-filled restorative systems Filtek Z-350 and Filtek Z-350 flow. Using a tensiometer, Marchese et al. $^{23}$ also observed that the contraction stress of a silorane-based composite is not lower than those of conventional methacrylatebased restorative materials.

The intensity of the developed stress is associated 
with three principal factors:

- cavity geometry (C-factor),

- material characteristics, and

- restorative technique. ${ }^{24}$

According to Suh et al., ${ }^{25}$ the contraction stress from polymerization is the result of the contraction associated with the modulus of elasticity of the composite resins: the higher the modulus, the higher the generated stress. As the stress contraction is calculated by multiplying the product of the volumetric contraction by the modulus of elasticity, ${ }^{23}$ a possible explanation for the equivalence among the stress values of the tested composites could be the high stiffness and high modulus of elasticity of the Filtek P-90, ${ }^{21}$ which could generate a higher contraction stress in addition to its reduced free contraction. According to Masouras et al., ${ }^{26}$ the composition of the filler is directly related to the modulus of elasticity of a composite. While both Filtek Z-350 and Filtek Z-350 flow are filled with regular spherical nanoparticles of silica, the P-90 filler is composed of irregular quartz particles, ${ }^{27}$ which may contribute to its higher modulus of elasticity.

One interesting point that was noted was the Filtek P-90 adhesive's higher contraction stress as compared to that of the etch-and-rinse 2-step adhesive. Although the viscosities of the materials were not measured, the P-90 visually appeared to be much more viscous, which has the potential to lead to a thicker adhesive layer and greater influence on the final contraction stress of the restoration. According to the manufacturer's information, neither adhesive nor primer possesses silorane in its

\section{References}

1. Stansbury JW. Curing dental resins and composites by photopolymerization. J Esthet Dent. 2000;12(6):300-8.

2. Kinomoto Y, Torii M, Takeshige F, Ebisu S. Polymerization contraction stress of resin composite restorations in a model Class I cavity configuration using photoelastic analysis. J Esthet Dent. 2000;12(6):309-19.

3. Bowen RL, Nemoto K, Rapson JE. Adhesive bonding of various materials to hard tooth tissues: forces developing in composite materials during hardening. J Am Dent Assoc. 1983 Apr;106(4):475-7. composition. The Filtek P-90 adhesive is filled with between $5 \%$ and $10 \%$ of silanized silica, which may explain the higher viscosity. It is therefore possible to predict that the restorative system Filtek P-90 may show a more deteriorative stress behavior than the etch-and-rinse 2-step adhesive system Single Bond 2 associated to Filtek Z-350.

The composite Z-350 flow (66\% filler by weight, $55 \%$ by volume) has less filler than the Z-350 (78\% filler by weight, $59 \%$ by volume), but this difference did not affect the contraction stress. This may be due to the viscosity modifiers in the Filtek Z-350 flow exerting greater influence on the final viscosity than does the amount of filler itself, which probably was not sufficient to modify the generation of stress.

Clinical studies have shown no difference in stress behavior between low-shrinkage and conventional materials. ${ }^{28}$ According to the authors, many factors associated with the clinical conditions, such as placement of the restoration using the incremental technique, could be the main reason for finding no difference between the materials. ${ }^{28}$

Based on the results of this study, the null hypothesis must be rejected, as the Filtek P-90 adhesive showed higher values of contraction stress.

\section{Conclusion}

Although the silorane-based composite showed similar contraction stress to that of the traditional composites, its adhesive system showed higher contraction stress than the etch-and-rinse 2-step adhesive. There was no benefit from the reduced contraction of the silorane-based materials on the generation of stress at the substrate interface.

4. Hegdahl T, Gjerdet NR. Contraction stresses of composite resin filling materials. Acta Odontol Scand. 1977;35(4):191-5.

5. Ernst CP, Meyer GR, Klocker K, Willershausen B. Determination of polymerization shrinkage stress by means of a photoelastic investigation. Dent Mater. 2004 May;20(4):313-21.

6. Condon JR, Ferracane JL. Assessing the effect of composite formulation on polymerization stress. J Am Dent Assoc. 2000 Apr;131(4):497-503. 
7. Feilzer AJ, de Gee AJ, Davidson CL. Setting stresses in composites for two different curing modes. Dent Mater. 1993 Jan;9(1):2-5.

8. Jedrychowski JR, Bleier RG, Caputo AA. Shrinkage stresses associated with incremental composite filling techniques. ASDC J Dent Child. 1998 Mar-Apr;65(2):111-5.

9. Porto IC, Soares LE, Martin AA, Cavalli V, Liporoni PC. Influence of the photoinitiator system and light photoactivation units on the degree of conversion of dental composites. Braz Oral Res. 2010 Oct-Dec;24(4):475-81.

10. Uno S, Asmussen E. Marginal adaptation of a restorative resin polymerized at reduced rate. Scand J Dent Res. 1991 Oct;99(5):440-4.

11. Watts DC, al Hindi A. Intrinsic 'soft-start' polymerisation shrinkage-kinetics in an acrylate-based resin-composite. Dent Mater. 1999 Jan;15(1):39-45.

12. Kinomoto Y, Torii M, Takeshige F, Ebisu S. Comparison of polymerization contraction stresses between self- and lightcuring composites. J Dent. 1999 Jul;27(5):383-9.

13. Versluis A, Tantbirojn D, Douglas WH. Do dental composites always shrink toward the light?. J Dent Res. 1998 Jun;77(6):1435-45.

14. Davidson CL, de Gee AJ. Relaxation of polymerization contraction stresses by flow in dental composites. J Dent Res. 1984 Feb;63(2):146-8.

15. Carvalho RM, Pereira JC, Yoshiyama M, Pashley DH. A review of polymerization contraction: the influence of stress development versus stress relief. Oper Dent. 1996 JanFeb;21(1):17-24.

16. Craig RG, el-Ebrashi MK, LePeak PJ, Peyton FA. Experimental stress analysis of dental restorations. I. Two-dimensional photoelastic stress analysis of inlays. J Prosthet Dent. 1967 Mar;17(3):277-91.

17. Standlee JP, Caputo AA. Load transfer by fixed partial dentures with three abutments. Quintessence Int. 1988 Jun;19(6):40310.
18. Rohrbach C. Handbook für esperimentelle Spannungsanalyse. Düsseldorf: VDI-Verlag 1989. 886 p.

19. Kinomoto Y, Torii M. Photoelastic analysis of polymerization contraction stresses in resin composite restorations. J Dent. 1998 Mar;26(2):165-71.

20. Rees JS, Jacobsen PH. Stresses generated by luting resins during cementation of composite and ceramic inlays. J Oral Rehabil. 1992 Mar;19(2):115-22.

21. Weinmann W, Thalacker C, Guggenberger R. Siloranes in dental composites. Dent Mater. 2005 Jan;21(1):68-74.

22. Bouillaguet S, Gamba J, Forchelet J, Krejci I, Wataha JC. Dynamics of composite polymerization mediates the development of cuspal strain. Dent Mater. 2006 Oct;22(10):896-902.

23. Marchesi G, Breschi L, Antoniolli F, Di Lenarda R, Ferracane $\mathrm{J}$, Cadenaro M. Contraction stress of low-shrinkage composite materials assessed with different testing systems. Dent Mater. 2010 Oct;26(10):947-53.

24. Unterbrink GL, Liebenberg WH. Flowable resin composites as "filled adhesives": literature review and clinical recommendations. Quintessence Int. 1999 Apr;30(4):249-57.

25. Suh BI, Feng L, Wang Y, Cripe C, Cincione F, de Rjik W. The effect of the pulse-delay cure technique on residual strain in composites. Compend Contin Educ Dent. 1999 Feb;20(2 Suppl):4-12; quiz 3-4.

26. Masouras K, Akhtar R, Watts DC, Silikas N. Effect of filler size and shape on local nanoindentation modulus of resincomposites. J Mater Sci Mater Med. 2008 Dec;19(12):3561-6.

27. Leprince J, Palin WM, Mullier T, Devaux J, Vreven J, Leloup G. Investigating filler morphology and mechanical properties of new low-shrinkage resin composite types. J Oral Rehabil. 2010 May 1;37(5):364-76.

28. Schmidt M, Kirkevang LL, Horsted-Bindslev P, Poulsen S. Marginal adaptation of a low-shrinkage silorane-based composite: 1-year randomized clinical trial. Clin Oral Investig. Forthcoming 2010. 